УДК 342.156

DOI: $10.17223 / 22253513 / 32 / 8$

\title{
Е.Ю. Тихонравов
}

\section{НЕЗАКОННАЯ АННЕКСИЯ ТЕРРИТОРИИ ГОСУДАРСТВА КАК ОСНОВАНИЕ ДЛЯ ПРЕКРАЩЕНИЯ ЕГО СУЩЕСТВОВАНИЯ}

\begin{abstract}
В научной литературе дискутируется вопрос, приводит ли незаконная аннексия всей территории государства к прекращению его существования. Одни специалисты отрииают такое последствие, другие же его признают. Для преодоления этого спора в статье выделены элементы, являющиеся для любой государственной организации конститутивными. Затем показано, устраняет ли полная аннексия территории государства хотя бы один из них. Все это позволило определить верную позицию в упомянутой дискуссии.

Ключевые слова: аннексия, оккупация, суверенитет, незаконное применение силь.
\end{abstract}

Захват одним государством территории другого посредством угрозы силой или применения последней образует аннексию [1. § 1]. При этом она может быть либо полной, либо частичной. В первом случае захвату подлежит вся государственная территория, во втором - только ее часть.

В прошлом международное право не устанавливало обязанность государств воздерживаться в их международных отношениях от угрозы силой или ее применения. В связи с этим аннексия рассматривалась в качестве правомерного способа приобретения территории [1. § 4; 2. Р. 501, 532]. Однако после Первой мировой войны ситуация изменилась. Упомянутая обязанность нашла свое отражение в международном праве и содержится в нем до сих пор [1. § 10, 14; 2. Р. 501]. Данный факт преобразовал характер аннексии: теперь она квалифицируется как международно-противоправное деяние [1. § 4, 14].

Исходя из незаконного характера аннексии, специалисты выдвинули два противоречащих друг другу представления о результате захвата всей территории государства посредством угрозы силой или ее применения. В соответствии с первым подходом указанный захват не препятствует аннексированному государству продолжить свое существование. Согласно же второму полная аннексия вызывает гибель государственной организации, утратившей территорию.

Первый подход отстаивал, в частности, Р. Хофман. По словам этого юриста, «аннексия всей территории государства не приводит к его автоматическому исчезновению как субъекта международного права» [Ibid. § 15].

По мнению некоторых исследователей, изложенная теоретическая позиция соответствует практике государств. Например, Д. Крофорд отметил, что в XX в. она «выработала положение... согласно которому [полная] ан- 
нексия территории государства как результат незаконного применения силы не влечет прекращения его существования» [3. Р. xxxviii].

Кроме того, в правоведении сформулирована точка зрения, что государство, незаконно аннексировавшее территорию другого, не приобретает суверенитета над ней [4. Р. 106]. Последний, полагал Р. Лангер, может принадлежать «выжившей в той или иной форме... суверенной власти, лишенной территории» [Ibid. P. 101]. Именно так обстоят дела при образовании правительства в изгнании [Ibid.].

Немало ученых-юристов иллюстрировали приведенные идеи на примере прибалтийских стран. Как известно, в августе 1940 г. Латвия, Литва и Эстония были приняты в состав СССР на правах союзных республик. При этом советский правящий класс рассматривал состоявшуюся инкорпорацию правомерной [5. С. 146]. Однако ряд специалистов придерживаются противоположной позиции. Она сводится к тому, что упомянутое присоединение произошло посредством незаконной оккупации Красной Армией прибалтийских стран с их дальнейшей аннексией Советским Союзом $[1, \S 32$; 6. Р. 380-382, 389-390].

Основываясь на такой интерпретации исторических событий, связанных с недобровольным вхождением Латвии, Литвы и Эстонии в состав СССР в 1940 г., Л. Мялксоо посчитал нужным отметить следующее. «Незаконность советской аннексии, непризнание этой аннексии западными странами, оказанное балтийскими народами сопротивление советскому режиму и непрерывное функционирование рудиментарных государственных органов в изгнании вынуждают нас сделать итоговый вывод в пользу континуитета ${ }^{1}$ стран Балтии на протяжении советской аннексии. Непризнание западными странами лишь дополнительно подтвердило незаконность аннексии. В результате этой незаконности, подтвержденной непризнанием, Советский Союз не приобрел правооснования. Если не выдвигать очевидно абсурдного предположения, что страны Балтии стали terrae nullius [ничейной землей], то суверенитет принадлежал находившимся в изгнании структурам незаконно оккупированных стран Балтии» [8. С. 232].

Л. Мялксоо конкретизировал свои суждения по отношению к Эстонской Республике. По его словам, сформированное правительство упомянутого государства в изгнании «представляло собой акт сознательного неприятия советского режима со стороны соответствующего населения и тем самым не позволяло этому режиму стать неоспоримым. Подобная капитуляция могла бы привести к окончательному прекращению существования Эстонской Республики как субъекта международного права» [Там же. С. 184].

Аналогичные представления были сформулированы другими исследователями по отношению к Литовской Республике. Скажем, по убеждению

\footnotetext{
${ }^{1}$ Понятие «континуитет» используется для обозначения ситуаций, в которых «правосубъектность и конкретные права и обязанности государства остаются неизменными» [7. P. 80].
} 
Р. Витаса, основанием «для продолжающегося существования Литвы выступил юридический принцип, согласно которому результаты незаконных действий не в состоянии стать правомерными. Несмотря на то, что Литва была de facto оккупирована, аннексия являлась ничтожной и недействительной... Таким образом, военная оккупация Литвы не привела к переходу какого-либо титула на территорию [Литвы] к Советскому Союзу и не устранила независимое правительство [литовской] нации» [9. Р. 253].

Изложенному теоретическому подходу противостоит другой. Как уже сказано, в соответствии с ним государство, полностью утратившее территорию в результате незаконной аннексии, прекращает свое существование.

Например, этого взгляда придерживался Г. Кельзен. Он заявлял, что утверждение, согласно которому «незаконно аннексированная группа лиц... не прекращает своего существования как государство, предполагает фикцию, находящуюся в противоречии с правовой реальностью» [10. Р. 225].

Сходную идею изложил и У. Шойнер. По его убеждению, незаконность аннексии не способна вызвать никаких изменений в произошедшей в результате последней «гибели государства» [11. S. 20].

Второму рассматриваемому теоретическому подходу соответствуют рассуждения Р. Арона и К. Марек о вхождении Латвии, Литвы и Эстонии в состав СССР в 1940 г. Первый из двух названных исследователей утверждал, что вследствие отмеченного присоединения «прибалтийские страны перестали существовать и больше не являются субъектами права» [12. Р. 108]. Причем указанный итог этой инкорпорации, полагал Р. Арон, не зависит от ее соответствия правовым нормам. Ведь «те основные исторические события, в силу которых государства рождаются и умирают, происходят вне юридической системы» [Ibid.].

Что касается К. Марек, то в 1968 г. она писала: «Есть достаточно серьезные основания, свидетельствующие о прекращении существования прибалтийских стран. Они полностью утратили свою территорию. Их население приобрело устойчивую связь с другим государственным порядком [т.е. с государственным порядком СССР]. Их собственный правовой порядок нигде не является эффективным» [6. Р. 398], ибо «в прибалтийских странах... осуществляется эффективный советский контроль» [Ibid.].

При этом К. Марек считала, что в 1940 г. «Красная Армия оккупировала Эстонию, Латвию и Литву» [Ibid. Р. 380]. Затем, по ее словам, СССР провел «насильственную аннексию прибалтийских государств» [Ibid. P. 390], которая «являлась противоправным действием как по обычному, так и по конвенциональному международному праву» [Ibid.].

Чтобы преодолеть противоречие между изложенными теоретическими подходами, необходимо решить две задачи. Прежде всего нужно установить, какие элементы являются для государственной организации конститутивными. Затем следует ответить на вопрос, устраняется ли хотя бы один из них в результате полной аннексии территории государства. Очевидно, что в случае отрицательного ответа верным окажется первый теоретический подход, а при положительном - второй. 
При выделении конститутивных для государственной организации элементов многие исследователи опираются на учение юридического позитивизма [13. С. 9-10]. В соответствии с этой концепцией государство представляет собой любое человеческое сообщество, которое состоит из суверена и подданных. Под первым понимается индивид или коллектив, «никому привычно не подчиняющийся» [14. Р. 89]. Подданные - это остальные члены рассматриваемого сообщества, которые «находятся в привычном повиновении» суверену [Ibid. P. 90]. Причем последнее выражается в виде их подчинения общеобязательным социальным нормам. Эти правила, также называемые юридическими либо правовыми, формулируются сувереном и адресуются им подданным.

Что касается аннексии, то она выступает частным случаем территориальных изменений, при которых вся либо часть территории одного государства переходит к другому. Вот почему общие закономерности упомянутых трансформаций характерны и для аннексии.

Для достижения цели настоящей работы среди указанных закономерностей надлежит выделить следующие. Прежде всего, как отметил Г. Еллинек, территория «как таковая... не может быть объектом государственного господства» [15. С. 391]. Ведь она служит «пространственным основанием для осуществления власти государства над всеми пребывающими в государстве людьми - подданными и иностранцами» [Там же. С. 387]. Отсюда ясно, что «не может существовать отдельного от господства над лицами территориального верховенства» [Там же. С. 389]. Иными словами, «государство никогда не может господствовать над своей территорией непосредственно, помимо своих подданных» [Там же. С. 387].

Сделанный вывод, заявлял Г. Еллинек, не отрицается «фактом существования ненаселенных территорий» [Там же. С. 390]. Действительно, «ненаселенная территория является всегда возможной сферой осуществления государственной власти, и это осуществление может происходить только таким же образом, как и в стране обитаемой» [Там же].

Сказанное дает возможность прийти к следующему заключению. Когда вся либо часть территории одного государства переходит к другому, то объектом этого перехода выступает «не мертвая территория» [Там же. C. 391], а «господство над пребывающими в пределах территории людьми» [Там же].

Таким образом, отмеченные территориальные изменения могут состояться лишь в одном случае. Имеется в виду прекращение повиновения населения соответствующей территории прежнему суверену и наличие их подчинения новому.

Очевидно, что в ситуации, когда отторжению подлежит часть территории государства, его суверенная власть сохраняет повиновение подданных на остальном государственном пространстве. Однако при переходе всей территории государства дела обстоят иначе. В ее пределах отсутствуют подданные, демонстрирующие подчинение суверену этой государственной организации. 
Для последнего данный факт означает вполне определенное последствие, на которое, в частности, указал Г. Еллинек. Он утверждал, что «повиновение всей совокупности подданных... пополняет государственную власть, и без него она не может существовать» [15. С. 412]. Другими словами, суверен, подданные которого прекратили оказывать ему подчинение, перестает быть таковым.

Правда, в приведенном суждении Г. Еллинека содержится неточность. По его мнению, для существования государственной власти требуется «повиновение всей совокупности подданных». Однако едва ли это положение соответствует действительности. Как известно, для функционирования суверенной власти достаточно подчинения ей большинства подданных, а не всей их совокупности [16. Р. 96].

Отмеченная неточность не препятствует констатации следующего вывода: при переходе всей территории одного государства к другому в первом из них становится невозможным выделить суверена и подданных, т.е. те два элемента, объединение которых только и способно образовать государственную организацию. Вот почему каждое государство, чья территория полностью перешла к иному, прекращает свое существование.

Разумеется, только что сформулированная общая закономерность распространяется и на полную аннексию территории любой государственной организации. Иными словами, государство, подвергнувшееся такой аннексии, перестает существовать. Отсюда ясно, что первый из двух рассмотренных в настоящей статье теоретических подходов является неверным.

Скорее всего, так же необходимо оценить приведенное в ее начале воззрение, которого, в частности, придерживался Р. Лангер. Речь идет о суждении, что государство, аннексировавшее территорию другого, не приобретает над ней суверенитета.

Аргументация, доказывающая неверность этого взгляда, может быть следующей. Как известно, суверенитет есть свойство государственной власти, в силу которого «она является верховной и независимой от всякой другой власти в осуществлении своих функций как внутри страны, так и во взаимоотношениях с другими государствами» [17. С. 35]. Причем «реализация суверенитета государственной власти осуществляется прежде всего посредством правотворческой деятельности, т.е. путем придания определенным правилам юридической силы» [Там же. С. 36]. Кроме того, «суверенитет государственной власти проявляется и в осуществлении, в том числе и принудительном, установленных государством общеобязательных норм» [Там же].

Как отмечено ранее, переход территории одного государства к другому, в том числе посредством угрозы силой или ее применения, может состояться в единственном случае. Имеется в виду, что население этой территории перестает повиноваться суверену первого государства и начинает подчиняться суверенной власти второго.

На основе уже раскрытого понятия подчинения суверенной власти подданных возможно продемонстрировать суть перехода упомянутого повиновения от одного суверена к другому. Этот смысл сводится к следующе- 
му. Находящееся на передаваемой территории население прекращает проводить в жизнь юридические правила прежней суверенной власти и начинает исполнять нормы права, адресуемые ему новым сувереном.

Сказанное позволяет сделать очевидный вывод. Переход территории одного государства к другому требует, чтобы политическое руководство последнего выполняло на ней функции, реализация которых традиционно рассматривается в юриспруденции как претворение в жизнь суверенитета государственной власти. Речь идет о правотворческой деятельности и осуществлении установленных государством общеобязательных норм. Вот почему обсуждаемые территориальные изменения всегда предполагают переход суверенитета от государственной власти, утратившей территорию, к государственной власти, ее получившей.

Так происходит и в случае, когда территориальные изменения были достигнуты с нарушением юридических правил, например путем незаконной аннексии. В самом деле, из принятой в юриспруденции интерпретации суверенитета государственной власти следует, что его существование обусловливается не законностью установления последней, а выполнением основной массой подданных большинства общеобязательных правил, создаваемых сувереном.

Скорее всего, приведенной аргументации достаточно для того, чтобы показать неверность теоретической позиции Р. Лангера. Таким образом, это воззрение нужно отвергнуть.

Сформулированные заключения возможно применить и к вхождению Латвии, Литвы и Эстонии в состав СССР в 1940 г. Как известно, вследствие указанного присоединения население прибалтийских стран прекратило повиноваться структурам, которые представляли суверенную власть этих государств до отмеченной инкорпорации. Суверенные же полномочия на территории Латвии, Литвы и Эстонии стал выполнять СССР. Прежде всего это выразилось в правотворческой деятельности и осуществлении советской государственной властью установленных ею общеобязательных норм. Причем основная масса лиц на территории прибалтийских республик реализовывала большинство этих предписаний. Отсюда ясно, что суверенная власть, действовавшая в Латвии, Литве и Эстонии до обсуждаемого присоединения, после него перестала быть таковой. Вот почему и сами эти государства прекратили свое существование.

Правда, отдельные страны отказались признавать результат вхождения Латвии, Литвы и Эстонии в состав СССР. Например, так поступили США. По словам М.В. Коротковой, «то, что США не признают присоединение, стало очевидным еще до завершения [этого] процесса» [18. С. 208]. Действительно, 23 июля 1940 г. исполняющий обязанности государственного секретаря США С. Уэллес обнародовал декларацию, демонстрирующую намерение США не признавать проводимую инкорпорацию Латвии, Литвы и Эстонии из-за ее неправомерности [6. Р. 399].

Указанная политика непризнания нашла свое отражение и в заявлениях некоторых президентов США. В частности, 15 октября 1940 г. Ф. Рузвельт 
провел в Белом доме встречу с литовской делегацией. Последняя представила ему меморандум, где было сказано, что «Литва утратила свою независимость» [9. Р. 251]. «Это неверно, - возразил Ф. Рузвельт. - Независимость Литвы не утеряна...» [Ibid.].

Аналогичное заявление сделал Р. Рейган. В июне 1983 г. он подтвердил, что «правительство США никогда не признавало насильственную инкорпорацию прибалтийских стран в состав Советского Союза и не сделает этого в будущем» [19. Р. 22, 23]. Наконец, в августе 1991 г. Д. Буш подчеркнул, что США «никогда не признавали насильственный захват [прибалтийских стран Советским Союзом]... Наша позиция по этому вопросу, - отметил Д. Буш, - состоит в том, что они [прибалтийские страны] до сих пор являются независимыми» [Ibid. P. 26].

Смысл подобных заявлений достаточно точно раскрыл Г. Кельзен. В соответствии с его представлениями, «государство может публично объявить о непризнании аннексии другого государства третьей страной, так как эта аннексия влечет нарушение международного права. Если, однако, данная аннексия эффективна, иными словами, твердо установлена, то правительство непризнающего государства не в состоянии утверждать, что инкорпорированная группа людей все еще обладает всеми элементами, присущими государству в смысле международного права. Отсюда «непризнание» не может подразумевать мнения непризнающего правительства, что неправомерно инкорпорированный коллектив лиц продолжает существовать как независимое государство. "Непризнание” способно иметь политическое значение. Оно может выражать определенное порицание со стороны непризнающего правительства и желание последнего видеть неправомерно аннексированную общность индивидуумов восстановленной в качестве независимого государства» [10. Р. 224, 225].

Указанные суждения Г. Кельзена предполагают уважение права каждой конкретной страны принимать самостоятельное решение о непризнании факта прекращения существования государства в результате аннексии всей его территории. Другое дело, что отдельные специалисты, как было продемонстрировано ранее, отрицают указанный итог полной аннексии в рамках юриспруденции как научной дисциплины. С таким теоретическим подходом, подвергнутым критике в настоящей статье, согласиться нельзя. Причина проста. Этот подход ориентирует исследователей видеть наличие государственной организации и соответствующего ей суверенитета в тех обстоятельствах, в которых они в действительности отсутствуют, и тем самым способен ввести юристов в заблуждение.

\section{Литература}

1. Max Planck Encyclopedia of Public International Law: Annexation. URL: http://opil.ouplaw.com/view/10.1093/law:epil/9780199231690/law-9780199231690-e1376

2. Shaw M. International Law. Cambridge : Cambridge University Press, 2008. 1542 p.

3. Crawford J. The Creation of States in International Law. Oxford : Oxford University Press, 2011. 870 p. 
4. Langer R. Seizure of Territory: the Stimson Doctrine and Related Principles in Legal Theory and Diplomatic Practice. Princeton : Princeton University Press, 1947. 313 p.

5. Заседания Верховного Совета СССР шестого созыва. Шестая сессия : стенографический отчет. М. : Изд. Верховного Совета СССР, 1965. 360 с.

6. Marek K. Identity and Continuity of States in Public International Law. Geneva : Droz, 1968. $613 \mathrm{p}$.

7. Brownlie I. Principles of Public International Law. Oxford : Oxford University Press, 2003. $784 \mathrm{p}$.

8. Мялксоо Л. Советская аннексия и государственный континуитет: международноправовой статус Эстонии, Латвии и Литвы в 1940-1991 гг. и после 1991 г. Тарту : Издательство Тартуского университета, 2005. 399 с.

9. Vitas R. The Recognition of Lithuania: the Completion of the Legal Circle // Journal of Baltic Studies. 1993. Vol. 24. P. 247-262.

10. Kelsen H. General Theory of Law and State. New Jersey : Transaction Publishers, 2007. $516 \mathrm{p}$.

11. Scheuner U. Die Funktionsnachfolge und das Problem der staatsrechtlichen Kontinuitaet // Vom Bonner Grundgesetz zur gesamtdeutschen Verfassung (Festschrift fuer Franz Nawiasky) / T. Maunz (Hg.). Muenchen : Isar Verlag, 1956. S. 9-48.

12. Aron R. Peace and War: a Theory of International Relations. New Jersey : Transaction Publishers, 2003. 820 p.

13. Емцов Г.Н. Государство и право в условиях гражданской войны : автореф. дис. ... канд. юрид. наук. Красноярск, 2004. 17 с.

14. Austin J. Lectures on Jurisprudence or The Philosophy of Positive Law. London : John Murray, 1869. 1169 p.

15. Еллинек Г. Общее учение о государстве. СПб. : Юрид. центр Пресс, 2004. 752 с.

16. Easton D. Framework for Political Analysis. Chicago : Chicago University Press, 1979. $160 \mathrm{p}$.

17. Митин С.С. Государственная власть: понятие и закономерности организации: дис. ... канд. юрид. наук. Красноярск, 2004. 181 с.

18. Короткова М.В. Политика США по непризнанию вхождения прибалтийских республик в состав СССР // 1945 год: формирование основ послевоенного мироустройства. Киров, 2015. С. 208-213.

19. Waldern S.J. Lithuania: The Impact of the Stimson Doctrine. Sandy Bay : Tasmania University Union Lithuanian Studies Society, 1993. 33 p.

Tikhonravov Evgeny Y., Siberian Federal University (Krasnoyarsk, Russian Federation)

UNLAWFUL ANNEXATION OF TERRITORY OF A STATE AS THE BASIS FOR ITS EXTINCTION

Keywords: annexation, occupation, sovereignty, unlawful use of force.

DOI: $10.17223 / 22253513 / 32 / 8$

The scientific literature puts forward conflicting theoretical positions on the results of the illegal annexation of the entire state territory. According to the first, the annexed state continues to exist. According to the second said annexation leads to his death.

In addition, the jurisprudence discussed the question becomes whether the state, illegally annexing the territory of another, over her sovereignty. Some experts answer it negatively, others - positively.

The conflicting theoretical views expressed often lead to ambiguous assessments of situations involving the accession of some States to others. Thus, the entry of Latvia, Lithuania and Estonia into the USSR in 1940 gave rise to a discussion. According to some researchers and politicians, the Baltic countries continued to exist as independent States despite the said 
accession. Other experts believe that as a result of this incorporation it has become impossible to consider Latvia, Lithuania and Estonia as sovereign political entities.

The article attempts to overcome these controversial issues. To achieve this goal, it solved the following tasks. First, based on the concept of legal positivism, the elements that are constitutive for any state organization are highlighted. We are talking about the sovereign and his subjects. Then it is shown that the annexation of the entire territory of the state eliminates the sovereign power of the latter. That is why the annexed state itself ceases to exist.

Then the article reveals the concept of sovereignty of state power and its transformation in territorial changes. This analysis led to the following conclusion. Any transition of the territory of one state to another requires that the political leadership of the latter perform functions on it, the implementation of which is traditionally considered in law as the exercise of the sovereignty of state power. Thus, the annexation implies the transfer of sovereignty from the state power, which has lost the territory, to the state power, which has received it.

Finally, the article assesses the judgment according to which Latvia, Lithuania and Estonia did not cease to exist after joining the USSR in 1940. As you know, as a result of this incorporation, the population of the Baltic countries ceased to obey the structures that represented the sovereign power of these States before the said incorporation. Sovereign powers on the territory of Latvia, Lithuania and Estonia began to perform the USSR. It is clear from this that the state power that existed in Latvia, Lithuania and Estonia before the accession under discussion ceased to be such after it. That is why these States themselves ceased to exist.

\section{References}

1. Hoffman, R. (n.d.) Annexation. In: Max Planck Encyclopedia of Public International Law. [Online] Available from: http://opil.ouplaw.com/view/10.1093/law:epil/97801992316 90/law-9780199231690-e1376.

2. Shaw, M. (2008) International Law. Cambridge: Cambridge University Press.

3. Crawford, J. (2011) The Creation of States in International Law. Oxford: Oxford University Press.

4. Langer, R. (1947) Seizure of Territory: the Stimson Doctrine and Related Principles in Legal Theory and Diplomatic Practice. Princeton: Princeton University Press.

5. Supreme Soviet of the USSR. (1965) Zasedaniya Verkhovnogo Soveta SSSR shestogo sozyva. Shestaya sessiya: stenograficheskiy otchet [Sessions of the Supreme Soviet of the sixth convocation. Session Six: Transcript]. Moscow: Supreme Soviet of the USSR.

6. Marek, K. (1968) Identity and Continuity of States in Public International Law. Geneva: Droz.

7. Brownlie, I. (2003) Principles of Public International Law. Oxford: Oxford University Press.

8. Mälksoo, L. (2005) Sovetskaya anneksiya i gosudarstvennyy kontinuitet: mezhdunarodno-pravovoy status Estonii, Latvii i Litvy v 1940-1991 gg. i posle 1991 g. [Soviet annexation and state continuity: the international legal status of Estonia, Latvia and Lithuania in 1940-1991. and after 1991]. Tartu: Tartu University.

9. Vitas, R. (1993) The Recognition of Lithuania: the Completion of the Legal Circle. Journal of Baltic Studies. 24. pp. 247-262.

10. Kelsen, H. (2007) General Theory of Law and State. New Jersey: Transaction Publishers.

11. Scheuner, U. (1956) Die Funktionsnachfolge und das Problem der staatsrechtlichen Kontinuitaet. In: Maunz. T. (ed.) Vom Bonner Grundgesetz zur gesamtdeutschen Verfassung (Festschrift fuer Franz Nawiasky). Munich: Isar Verlag. pp. 9-48.

12. Aron, R. (2003) Peace and War: a Theory of International Relations. New Jersey: Transaction Publishers.

13. Emtsov, G.N. (2004) Gosudarstvo i pravo v usloviyakh grazhdanskoy voyny [State and law in the context of civil war]. Abstract of Law Cand. Diss. Krasnoyarsk. 
14. Austin, J. (1869) Lectures on Jurisprudence or The Philosophy of Positive Law. London: John Murray.

15. Jellinek, G. (2004) Obshchee uchenie o gosudarstve [General Doctrine of the State]. Translated from German. St. Petersburg: Yurid. tsentr Press. Press.

16. Easton, D. (1979) Framework for Political Analysis. Chicago: Chicago University

17. Mitin, S.S. (2004) Gosudarstvennaya vlast': ponyatie i zakonomernosti organizatsii [State power: the concept and patterns of organization]. Law Cand. Diss. Krasnoyarsk.

18. Korotkova, M.V. (2015) Politika SShA po nepriznaniyu vkhozhdeniya pribaltiyskikh respublik v sostav SSSR [The US policy of non-recognition of the entry of the Baltic republics into the USSR]. In: 1945 god: formirovanie osnov poslevoennogo miroustroystva [1945: the foundations of the post-war world order]. Kirov: [s.n.]. pp. 208-213.

19. Waldern, S.J. (1993) Lithuania: The Impact of the Stimson Doctrine. Sandy Bay: Tasmania University Union Lithuanian Studies Society. 